\title{
Triglycerides impair postischemic recovery in isolated hearts: roles of endothelin-1 and trimetazidine
}

\author{
LUCILLA D. MONTI, ${ }^{1}$ SONIA ALLIBARDI,${ }^{5}$ PIER MARCO PIATTI, ${ }^{2}$ \\ GIANPIETRO VALSECCHI, ${ }^{1}$ SABRINA COSTA, ${ }^{1}$ GUIDO POZZA, ${ }^{3}$ \\ SERGIO CHIERCHIA, ${ }^{4}$ AND MICHELE SAMAJA ${ }^{5}$ \\ ${ }^{1}$ Divisione di Medicina, ${ }^{2}$ Unita' di Malattie Metaboliche, Divisione di Medicina, ${ }^{3}$ Cattedra di Clinica \\ Medica Generale e Terapia Medica, Universita' Vita-Salute, ${ }^{4}$ Dipartimento di Cardiologia, \\ Istituto di Ricovero e Cura a Carattere Scientifico, Hospital San Raffaele, 20132 Milan; and \\ ${ }^{5}$ Dipartimento di Medicina, Chirurgia ed Odontoiatria-DiMCO, Ospedale San Paolo, \\ University of Milan, Milan I-20090, Italy
}

Received 29 December 2000; accepted in final form 8 May 2001

\begin{abstract}
Monti, Lucilla D., Sonia Allibardi, Pier Marco Piatti, Gianpietro Valsecchi, Sabrina Costa, Guido Pozza, Sergio Chierchia, and Michele Samaja. Triglycerides impair postischemic recovery in isolated hearts: roles of endothelin-1 and trimetazidine. Am J Physiol Heart Circ Physiol 281: H1122-H1130, 2001.-There is growing evidence that hypertriglyceridemia exacerbates ischemic injury. We tested the hypothesis that triglycerides impair myocardial recovery from low-flow ischemia in an ex vivo model and that such an effect is related to endothelin-1. Hyperglycemic (glucose concentration $=12 \mathrm{mmol} / \mathrm{l}$ ) and hyperinsulinemic (insulin concentration $=1.2 \mu \mathrm{mol} / \mathrm{l}$ ) isolated rat hearts were perfused with Krebs-Henseleit buffer $\left(\mathrm{Po}_{2}=670 \mathrm{mmHg}, \mathrm{pH} 7.4,37^{\circ} \mathrm{C}\right)$ added with increasing triglycerides $(0,1,000,2,000$, and $4,000 \mathrm{mg} / \mathrm{dl}, n=6-9 \mathrm{rats} / \mathrm{group})$. Hearts were exposed to 60 min of low-flow ischemia (10\% of basal coronary flow), followed by $30 \mathrm{~min}$ of reperfusion. We found that increasing triglycerides impaired both the diastolic $(P<0.005)$ and systolic $(P<0.02)$ recovery. The release of endothelin-1 during reperfusion increased linearly with triglyceride concentration $(P=0.0009)$. Elevated triglycerides also increased the release of nitrite and nitrate $\left(\mathrm{NO}_{\mathrm{x}}\right)$, the end products of nitric oxide, up to $6 \mu \mathrm{mol} / \mathrm{min}$. Trimetazidine $(1 \mu \mathrm{mol})$ further increased $\mathrm{NO}_{\mathrm{x}}$ release, blunted endothelin-1 release, and protected myocardial function during recovery. We conclude that high triglyceride levels impair myocardial recovery after low-flow ischemia in association with endothelin-1 release. The endothelium-mediated effect of triglycerides on both contractile recovery and endothelin-1 release is prevented by $1 \mu \mathrm{M}$ trimetazidine.
\end{abstract}

nitric oxide

ACCUMULATING EPIDEMIOLOGICAL EVIDENCE suggests that the situation characterized by elevated plasma triglycerides (TG) is associated with increased cardiovascular risk independent of factors such as hyperglycemia and elevated plasma cholesterol (3). Hypertriglyceridemia is also a critical risk factor for coronary heart disease (CHD) mortality in subjects with impaired glucose tol-

Address for reprint requests and other correspondence: L. D. Monti, Divisione di Medicina, IRCCS, Hospital San Raffaele, Via Olgettina 60, 20132 Milano, Italy (E-mail: lucilla.monti@hsr.it). erance or diabetes (18). Furthermore, hypertriglyceridemia is a common finding in survivors of acute myocardial infarction (27). This epidemiological evidence suggests that TG influence myocardial performance after ischemia-reperfusion independently of atherosclerosis progression.

Although its role in acute ischemia-reperfusion is controversial, endothelin-1 (ET-1) is known to exacerbate injury, likely via activation of ET type A receptors (9). Studies in isolated hearts showed that ET-1 release increases on early reperfusion after ischemia, thereby contributing to injury (7), and that ET-1 is a major factor that depresses cardiac function (6) and causes cell necrosis (8). These findings are consistent with other studies $(21,23,30)$ demonstrating a relationship between ET-1 and the pathogenesis of myocardial ischemia. In humans, acute hypertriglyceridemia stimulates ET-1 release in normal subjects (36). In addition, hypertriglyceridemia is related with elevated plasma levels of ET-1 in glucose-intolerant and type II diabetic patients with insulin resistance syndrome (37). However, on an experimental ground, a link among hypertriglyceridemia, ET-1, and the outcome of the ischemia-reperfusion injury is still lacking. The purpose of this study is to provide experimental evidence of that link by testing the hypothesis that TG exacerbate the injury driven by ischemia-reperfusion and that this phenomenon is linked to ET-1.

The isolated crystalloid-perfused heart may be a suitable model to test this issue in three steps: 1) evaluate the direct acute effect of high TG on postischemic recovery, 2) assess the link between the reperfusion injury and ET-1 release, and 3) evaluate the protection afforded by the piperazine drug trimetazidine (TMZ). No attempt is made to investigate the mechanism underlying ET-1 recognition by cardiac myocytes, because it is known to involve ET type A

The costs of publication of this article were defrayed in part by the payment of page charges. The article must therefore be hereby marked "advertisement" in accordance with 18 U.S.C. Section 1734 solely to indicate this fact. 
receptors $(9,10,19,43)$. However, by testing the effect of TMZ, a recognized anti-anginal and anti-ischemic agent (13), one may understand the site of action of TG. Indeed, TMZ inhibits the activity of 3-ketoacyl coenzyme A ( CoA) thiolase, the key enzyme of fatty acid $\beta$-oxidation, thereby increasing myocardial oxidative glucose metabolism (29), and the inability to utilize glucose for the oxidative metabolism increases cardiovascular risk in the presence of excess fatty acids (34). Citrate release is a useful index of the flux through the $\beta$-oxidation path (50). In addition, because inactivation of nitric oxide (NO) may play a prominent role in cardiovascular disease (15), we measured the release of nitrite and nitrate $\left(\mathrm{NO}_{\mathrm{x}}\right)$, the end products of $\mathrm{NO}$ metabolism, during the reperfusion as a probe to assess the viability of the endothelial cells.

To mimic the metabolic situation occurring in type II diabetic patients during the postprandial period, we selected hyperglycemic and hyperinsulinemic conditions. Indeed, hyperinsulinemia increases plasma ET-1 in humans (36) because insulin stimulates ET-1 secretion from human endothelial (17) and vascular smooth muscle cells (2). In this study, hearts perfused in the presence of increasing TG concentration ([TG]), as well as $10^{-6} \mathrm{M}$ TMZ, are exposed to low-flow ischemia and reperfused. Data will show that the postischemic injury is proportional to [TG] and ET-1 release and that the deleterious effects of elevated TG are prevented by TMZ.

\section{MATERIALS AND METHODS}

Heart perfusion. Male Sprague-Dawley rats $(250-280 \mathrm{~g}$ body wt) fed ad libitum were anesthetized with heparinized thiopental sodium $(10 \mathrm{mg} / 100 \mathrm{~g}$ body wt). Hearts were excised, immersed in isotonic saline solution $\left(20^{\circ} \mathrm{C}\right)$ and mounted on the perfusion system as described previously (44). The time required for these operations never exceeded $45 \mathrm{~s}$ and was typically in the $15-$ to $30-\mathrm{s}$ range. Langendorff perfusion started immediately with the media described below. A peristaltic pump (Gilson; Viliers Le Bel, France) delivered the medium at desired flows to the 8- $\mu \mathrm{m}$-pore-size filter (47-mm diameter, Nucleopore; Pleasanton, CA), the preheater, and the aortic cannula. All the components of the apparatus, including the heart chamber, the oxygenator, and the preheater, were connected to a $1,760-\mathrm{W}$ external water bath (Endocal, Neslab Instruments; Newington, $\mathrm{NH}$ ) kept at $37.5 \pm 0.5^{\circ} \mathrm{C}$. A latex balloon in the left ventricle was connected to a pressure transducer (model 52-9966, Harvard Apparatus; Natick, MA) to monitor myocardial performance (see Experimental protocol). An additional transducer connected to the aortic cannula provided the coronary perfusion pressure (CPP). A cannula was inserted into the pulmonary artery to collect the venous return and to monitor venous $\mathrm{PO}_{2}$ by an $\mathrm{O}_{2}$-sensing electrode (model 5300 Oxygen Monitor, Yellow Springs Instruments; Yellow Springs, OH). The investigation conforms to the guidelines in the Guide for the Care and Use of Laboratory Animals (National Institutes of Health, Publication No. 85-23, Revised 1985).

The perfusion media consisted of a Krebs-Henseleit buffer with $2.0 \mathrm{mmol} / \mathrm{l}$ free $\mathrm{Ca}^{2+}, 12 \mathrm{mmol} / /$ glucose, and $20 \mathrm{mU} / \mathrm{l}$ human recombinant insulin (Actrapid HM, Novo Nordisk; Rome, Italy) added with variable amounts $(22.5-90 \mathrm{ml} / \mathrm{l}$ perfusion medium) of Intralipid 20\% (Fresenius Kabi; Ve- rona, Italy). The medium composition was not changed during the protocol. Before dilution, Intralipid 20\% contained $200 \mathrm{~g} / \mathrm{l} \mathrm{TG}, 12 \mathrm{~g} / \mathrm{l}$ phospholipids, $25 \mathrm{~g} / \mathrm{l}$ glycerol, and 257-280 $\mathrm{mg} / \mathrm{l}$ cholesterol. Linoleic acid is the main fatty acid in TG (18 carbons, 2 cis double bonds), with linolenic, oleic, palmitic, and stearic acids accounting for $<50 \%$ of the total. Vitamin $\mathrm{E}$ present in the mixture partly inhibits oxidation of unsaturated double bonds (G. Arcuri and F. Kabi, unpublished communication).

In control hearts ( $\mathrm{TG}_{0}$ group, $n=9$ ), no Intralipid was added to the Krebs-Henseleit buffer. In the $\mathrm{TG}_{1,000}(n=9)$, $\mathrm{TG}_{2,000}(n=7)$, and $\mathrm{TG}_{4,000}(n=6)$ groups, Intralipid was added to the medium to yield [TG] $\sim 1,000,2,000$, and 4,000 $\mathrm{mg} / \mathrm{dl}$. The $\mathrm{TG}_{4,000}+\mathrm{TMZ}(n=5)$ group was similar to $\mathrm{TG}_{4,000}$ group, but with $10^{-6} \mathrm{M}$ freshly prepared TMZ (Servier Laboratories; Courbevoie, France). The medium was equilibrated at $\mathrm{PO}_{2}=670 \pm 6 \mathrm{mmHg}$ (means $\pm \mathrm{SE}$ ) and $\mathrm{PCO}_{2}=36 \pm 1 \mathrm{mmHg}$ in membrane oxygenators (45). The resulting $\mathrm{pH}$ was $7.38 \pm 0.01$ at $37^{\circ} \mathrm{C}$.

Myocardial performance was monitored by a LabView system (National Instruments, Austin, TX) running on Macintosh Quadra 700 (Apple; Cupertino, CA). Measurements included the heart rate (HR), the end-diastolic pressure (EDP), the peak systolic pressure (PSP), the maximal rates of pressure development $\left(+\mathrm{dP} / \mathrm{d} t_{\max }\right)$ and relaxation $\left(-\mathrm{dP} / \mathrm{d} t_{\max }\right)$, and the coronary perfusion pressure (CPP). From these parameters, we derived the left ventricular developed pressure $(\mathrm{LVDP}=\mathrm{PSP}-\mathrm{EDP})$ and LVDP $\cdot \mathrm{HR}$, which represents the myocardial contractile work. The resistance was calculated as $(\mathrm{CPP}-\mathrm{EDP}) /\left(\right.$ flow rate)/(ventricle weight) (11). The $\mathrm{O}_{2}$ uptake was calculated from the arteriovenous $\mathrm{Po}_{2}$ difference and flow rate.

Experimental protocol. All hearts were stabilized for 20 $\mathrm{min}$ at a flow rate of $15 \mathrm{ml} / \mathrm{min}$ for baseline measurements. During this period, the volume of the intraventricular balloon was adjusted to yield an EDP of $10 \pm 1 \mathrm{mmHg}$ and was kept constant afterward. Hearts were then subjected to lowflow ischemia for $60 \mathrm{~min}$ by reducing the flow to $1.5 \mathrm{ml} / \mathrm{min}$. After ischemia, hearts were reperfused for $30 \mathrm{~min}$ with the same flow rate used during baseline. The recovery of postischemic myocardial performance was evaluated at the end of the reperfusion either as an increase of EDP and CPP above baseline values ( $\triangle \mathrm{EDP}$ and $\triangle \mathrm{CPP}$, respectively) or as a percentage of $\mathrm{HR}, \mathrm{LVDP},+\mathrm{dP} / \mathrm{d} t_{\max },-\mathrm{dP} / \mathrm{d} t_{\max }$, and $\mathrm{LVDP} \cdot \mathrm{HR}$.

Measurements in the coronary effluent. Glucose was measured by a glucose-oxidase analyzer (Yellow Springs Instruments). Insulin was measured in a single assay [within-assay coefficient of variance (CV)-3.0\%, between-assay CV-5.0\%] with a microparticle enzyme immunoassay ( $\mathrm{pmol} / \mathrm{l}$, cross-reactivity with proinsulin <2\%; IMX, Abbott Laboratories; Abbott Park, IL). Free fatty acid, TG, citrate, and lactate were measured by automated enzymatic spectrofluorimetric methods adapted to COBAS FARA II (withinassay CV-3.0\%, between-assay CV-3.0\%; Hoffman-La Roche; Basel, Switzerland).

To measure ET-1, the coronary effluent was collected every $10 \mathrm{~min}$ for $30 \mathrm{~min}$ during the reperfusion, and the samples were extracted on SepPack C18 minicolumn (Amprep, Amersham International; Buckinghamshire, UK). The eluate was evaporated in a Speed Vac (model SC110, Savant Instruments; Farmingdale, NY). Samples were then reconstituted with $250 \mu \mathrm{l}$ radioimmunoassay buffer and assayed by a radioimmunoassay kit (Endothelin-1,2 High-sensitivity Assay System; Amersham International). The antiserum was a rabbit anti-ET-1 antibody, and the tracer was ${ }^{125}$ I-labeled ET-1. The assay sensitivity was $1.25 \mathrm{pg} / \mathrm{ml}$, with a typical within- and between-assay $\mathrm{CV}=3.0 \%$ and $11.9 \%$, respec- 
Table 1. Myocardial performance during baseline

\begin{tabular}{|c|c|c|c|c|c|c|c|}
\hline & $\mathrm{TG}_{0}(n=9)$ & $\begin{array}{l}\mathrm{TG}_{1,000} \\
(n=9)\end{array}$ & $\begin{array}{l}\mathrm{TG}_{2,000} \\
(n=7)\end{array}$ & $\begin{array}{l}\mathrm{TG}_{4,000} \\
(n=6)\end{array}$ & $P$ & $\mathrm{TG}_{4,000}+\mathrm{TMZ}$ & $P$ \\
\hline Triglycerides, mg/dl & $2 \pm 1$ & $952 \pm 69$ & $2,083 \pm 177$ & $3,882 \pm 150$ & $\mathrm{NA}^{*}$ & $3,809 \pm 76$ & $\mathrm{NS} \dagger$ \\
\hline $\mathrm{HR}$, beats/min & $253 \pm 10$ & $258 \pm 7$ & $252 \pm 15$ & $245 \pm 9$ & NS* & $244 \pm 9$ & $\mathrm{NS} \dagger$ \\
\hline Developed pressure, $\mathrm{mmHg}$ & $115 \pm 7$ & $93 \pm 8$ & $124 \pm 12$ & $138 \pm 16$ & NS* & $164 \pm 7$ & $\mathrm{NS}+$ \\
\hline $\mathrm{LVDP} \cdot \mathrm{HR}, \mathrm{mmHg} \cdot 1,000 \cdot \mathrm{min}^{-1}$ & $28.8 \pm 1.6$ & $23.6 \pm 1.9$ & $31.3 \pm 3.4$ & $33.6 \pm 3.8$ & NS* & $40.1 \pm 2.0$ & $\mathrm{NS} \dagger$ \\
\hline End-diastolic pressure, $\mathrm{mmHg}$ & $9.9 \pm 0.2$ & $9.1 \pm 0.4$ & $10.3 \pm 0.4$ & $11.8 \pm 0.7$ & NS* & $10.4 \pm 0.6$ & $\mathrm{NS} \dagger$ \\
\hline Perfusion pressure, $\mathrm{mmHg}$ & $82 \pm 9$ & $120 \pm 11$ & $121 \pm 12$ & $113 \pm 11$ & $0.05 *$ & $96 \pm 16$ & $\mathrm{NS} \dagger$ \\
\hline Resistance, $\mathrm{mmHg} \cdot \mathrm{ml}^{-1} \cdot \min \cdot \mathrm{g}$ & $4.79 \pm 0.57$ & $7.39 \pm 0.71$ & $7.37 \pm 0.79$ & $6.76 \pm 0.75$ & NS* & $5.75 \pm 1.07$ & $\mathrm{NS} \dagger$ \\
\hline$+\mathrm{dP} / \mathrm{d} t_{\max }, \mathrm{mmHg} / \mathrm{s}$ & $3,201 \pm 151$ & $2,542 \pm 196$ & $3,496 \pm 434$ & $3,487 \pm 287$ & NS* & $3,912 \pm 160$ & $\mathrm{NS} \dagger$ \\
\hline$-\mathrm{dP} / \mathrm{d} t_{\max }, \mathrm{mmHg} / \mathrm{s}$ & $2,110 \pm 148$ & $1,842 \pm 180$ & $2,263 \pm 239$ & $2,217 \pm 223$ & NS* & $2,714 \pm 137$ & $\mathrm{NS}+$ \\
\hline Venous [lactate], $\mathrm{mmol} / \mathrm{l}$ & $0.12 \pm 0.04$ & $0.16 \pm 0.07$ & $0.21 \pm 0.08$ & $0.17 \pm 0.02$ & NS* & $0.21 \pm 0.03$ & $\mathrm{NS} \dagger$ \\
\hline Venous $\mathrm{PO}_{2}, \mathrm{mmHg}$ & $205 \pm 32$ & $208 \pm 36$ & $193 \pm 43$ & $259 \pm 24$ & NS* & $163 \pm 11$ & $0.01 \dagger$ \\
\hline $\mathrm{O}_{2}$ uptake, $\mu \mathrm{mol} / \mathrm{min}$ & $9.8 \pm 0.7$ & $9.7 \pm 0.8$ & $10.0 \pm 0.9$ & $8.6 \pm 0.5$ & NS* & $10.6 \pm 0.2$ & $0.01 \dagger$ \\
\hline $\mathrm{O}_{2}$ uptake/LVDP $\cdot \mathrm{HR}, \mu \mathrm{mol} \cdot \mathrm{mmHg}^{-1} \cdot 1,000$ & $0.34 \pm 0.02$ & $0.42 \pm 0.03$ & $0.34 \pm 0.03$ & $0.27 \pm 0.02$ & NS* & $0.31 \pm 0.01$ & $\mathrm{NS} \dagger$ \\
\hline
\end{tabular}

Values are means $\pm \mathrm{SE} ; n$, no. of rats. TG, triglycerides; TMZ, trimetazidine; LVDP·HR, left ventricular developed pressure $\times($ HR); $+\mathrm{dP} / \mathrm{d} t_{\max }$, maximal rate of pressure development; $-\mathrm{dP} / \mathrm{d} t_{\max }$, maximal rate of pressure relaxation; NA, not applicable; NS, not significant. Myocardial performance was assessed during baseline perfusion with Krebs-Henseleit medium $\left(2 \mathrm{mmol} / / \mathrm{free} \mathrm{Ca}^{2+}, 12 \mathrm{mmol} / / \mathrm{glucose}, 20\right.$ $\mathrm{mU} / \mathrm{insulin}$, and variable amounts of TG). In control hearts (TGo group), no TG was added. In the TG $\mathrm{TG}_{1,000}, \mathrm{TG}_{2,000}, \mathrm{TG}_{4,000}$ groups, Intralipid was added to the medium to yield a TG concentration of $\sim 1,000,2,000$, and 4,000 mg/dl, respectively. In the TG $\mathrm{T}_{4,000}$ group, $10^{-6} \mathrm{M}^{2}$ of freshly prepared TMZ was added ( $\mathrm{TG}_{4,000}+\mathrm{TMZ}$ group). Media were equilibrated at $\mathrm{PO}_{2}=670 \pm 6 \mathrm{mmHg}$ and $\mathrm{PCO}_{2}=36 \pm 1 \mathrm{mmHg} ;$ resulting $\mathrm{pH}$ was $7.38 \pm 0.01$ at $37^{\circ} \mathrm{C}$. Flow was $15 \mathrm{ml} / \mathrm{min}$. ${ }^{*} P>0.05$, analysis of variance test vs. TG; $\dagger P>0.05$, Student's $t$-test vs. TG 4,000 group.

tively. The total release of ET-1 during the reperfusion was calculated by taking the area under the curves representing ET-1 versus time by the trapezoidal rule and by considering, as a basal value, the ET-1 level measured at the end of ischemia.

$\mathrm{NO}_{\mathrm{x}}$ was measured by enzymatic catalysis coupled with the Griess reaction (49). As for ET-1, total $\mathrm{NO}_{\mathrm{x}}$ release during reperfusion was calculated by measuring the area under the curves representing $\mathrm{NO}_{\mathrm{x}}$ versus time by the trapezoidal rule, after taking the $\mathrm{NO}_{\mathrm{x}}$ level measured at the end of ischemia as the basal value.

Statistics. Data are expressed as means $\pm \mathrm{SE}$. To assess the effect of increasing [TG], we performed a two-way factorial analysis of variance test (StatView, Abacus Concepts; Berkeley, CA). To assess the effects of TMZ at constant [TG], we used Student's $t$-test. Simple regression analysis was performed using the indices of myocardial performance at recovery as the dependent variables and TG or ET-1 levels as the independent variables.

\section{RESULTS}

The concentration of glucose and insulin in the media were $12.5 \pm 0.5 \mathrm{mmol} / \mathrm{l}$ and $1.22 \pm 0.03 \mu \mathrm{mol} / \mathrm{l}$, respectively. The level of free fatty acids was $<0.2$ $\mathrm{mmol} / \mathrm{l}$ in both the arterial inflow and venous effluent. Because all hearts kept contracting through the ischemia-reperfusion protocol, all data were available for analysis. Table 1 shows myocardial performance during baseline. All parameters (except for CPP) were not altered by the increase of TG. Although increased in the $\mathrm{TG}_{1,000}$ group, resistance was not further altered for fourfold Intralipid increases. There was no effect of TMZ during baseline except for the higher $\mathrm{O}_{2}$ uptake in the $\mathrm{TG}_{4,000}+\mathrm{TMZ}$ group, which reflects the slightly improved, albeit nonsignificant, performance in TMZ hearts. Despite some intergroup differences in the $\mathrm{O}_{2}$ uptake-to-LVDP.HR ratio, which helps to address the relative contribution of carbohydrates and lipids to energy production, there is no [TG]-associated trend or significant effects of TMZ.
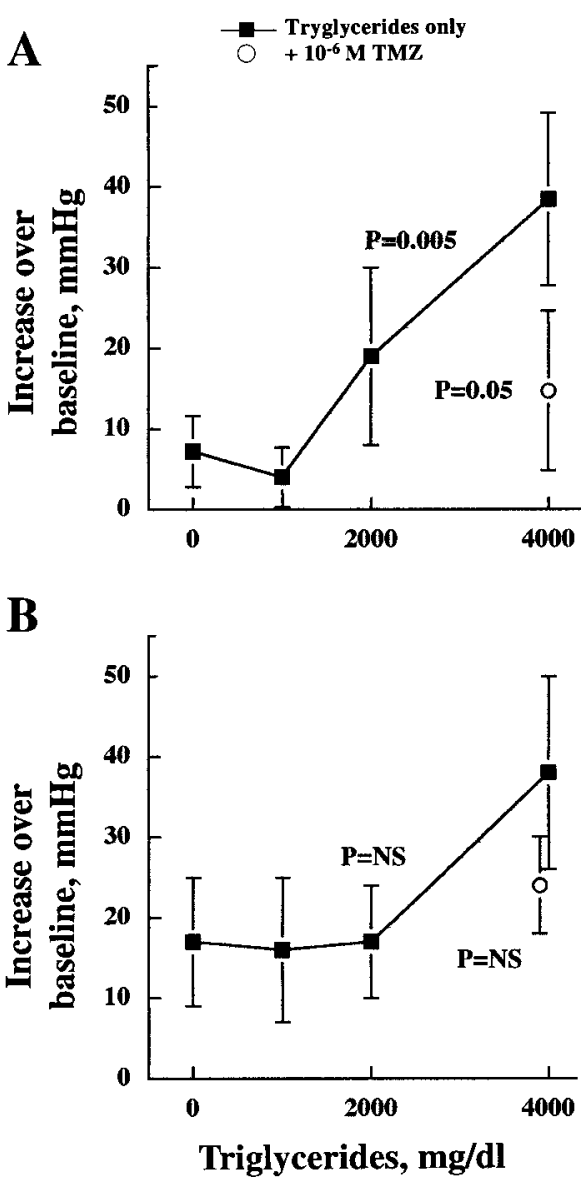

Fig. 1. Increase of the end-diastolic pressure $(A)$ and of the coronary perfusion pressures $(B)$ over baseline as measured at the end of reperfusion. Left $P$ values indicate the significance of the trend as a function of increasing triglycerides (one-way factorial analysis of variance test applied to the linear regression). Right $P$ values indicate the significance of the effect of $10^{-6} \mathrm{M}$ trimetazidine (TMZ) compared with the value corresponding to triglyceride concentration $($ [triglycerides] $)=4,000 \mathrm{mg} / \mathrm{dl}$. Data are means $\pm \mathrm{SE}$. NS, not significant. 

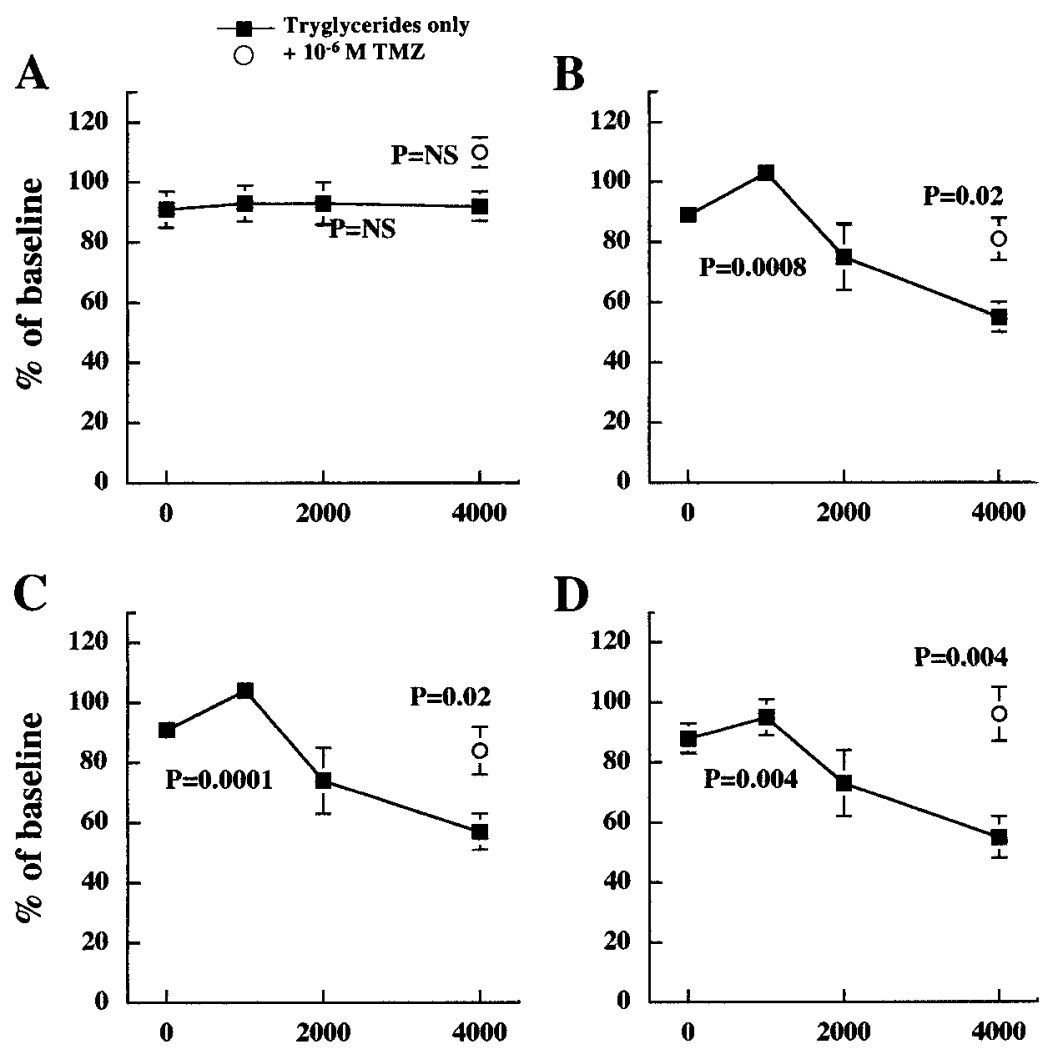

D

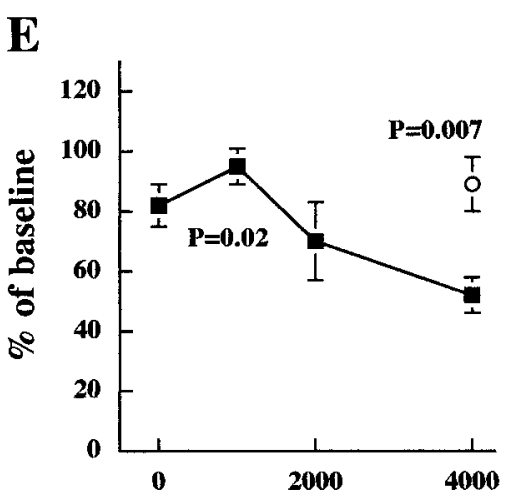

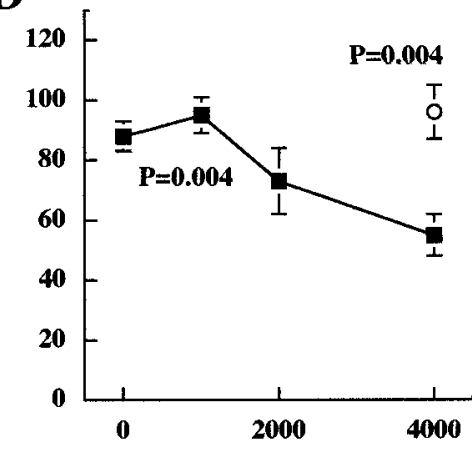

Triglycerides, mg/dl
Fig. 2. Recovery of heart rate (HR) $(A)$, left ventricular developed pressure (LVDP) $(B)$, maximal rates of pressure development $(C)$ and relaxation $(D)$, and crossproduct LVDP.HR $(E)$, expressed as percentage of the baseline value. Data are means \pm SE (see Fig. 1 ).

\section{Triglycerides, mg/dl}

The exposure of hearts to 60 -min low-flow ischemia, followed by 30 -min reperfusion, impaired myocardial performance. Increasing [TG] further impaired recovery. $\triangle \mathrm{EDP}$ increased with increasing [TG] $(P=0.005)$ up to $38.5 \pm 10.7 \mathrm{mmHg}$ (Fig. $1 A$ ). $\Delta \mathrm{CPP}$ tended to increase, although nonsignificantly $(P=0.08)$. The presence of $10^{-6} \mathrm{M}$ TMZ in the medium blunted $(P=$ $0.05)$ the increase in EDP; $\triangle \mathrm{CPP}$ tended to decrease, although nonsignificantly $(P=0.07)($ Fig. $1 B)$. Figure 2 shows other parameters of the ventricular function. HR was not affected by TG, but TMZ increased HR at the end of the postischemic recovery $(P=0.03)$. The recovery of LVDP was progressively impaired by the increase of [TG] to $55 \pm 5 \%$ of baseline $(P=0.0008)$. However, $10^{-6}$ M TMZ significantly $(P=0.02)$ protected hearts and increased the recovery of developed pressure to $81 \pm 7 \%$ baseline. The same trend as that described for LVDP was also observed for $+\mathrm{dP} / \mathrm{d} t_{\max }$, $-\mathrm{dP} / \mathrm{d} t_{\max }$, and LVDP.HR.

Figure $3, A$ and $B$, shows that increasing [TG] augments ET-1 release during reperfusion from $0.9 \pm 0.2 \mathrm{ng} / \mathrm{min}$ in the absence of TG to $6.3 \pm 1.6$ $\mathrm{ng} / \mathrm{min}$ in the presence of $4,000 \mathrm{mg} / \mathrm{dl} \mathrm{TG}(P=0.001)$. The presence of $10^{-6} \mathrm{M}$ TMZ completely blunted the release of ET-1 $(P=0.008)$. Figure $3, C$ and $D$, shows that increasing [TG] slightly increased the release of $\mathrm{NO}_{\mathrm{x}}$. The release of $\mathrm{NO}_{\mathrm{x}}$ appeared to be blunted when $[\mathrm{TG}]=2,000 \mathrm{mg} / \mathrm{dl}$ because a further [TG] increase did not augment $\mathrm{NO}_{\mathrm{x}}$ release. However, in the presence of $10^{-6} \mathrm{MTMZ}$, the release of $\mathrm{NO}_{\mathrm{x}}$ was augmented threefold with respect to the same [TG] in the absence of TMZ. Figure $3 E$ shows that the release of citrate increases linearly with [TG] and is blunted in the presence of $10^{-6} \mathrm{M}$ TMZ. 

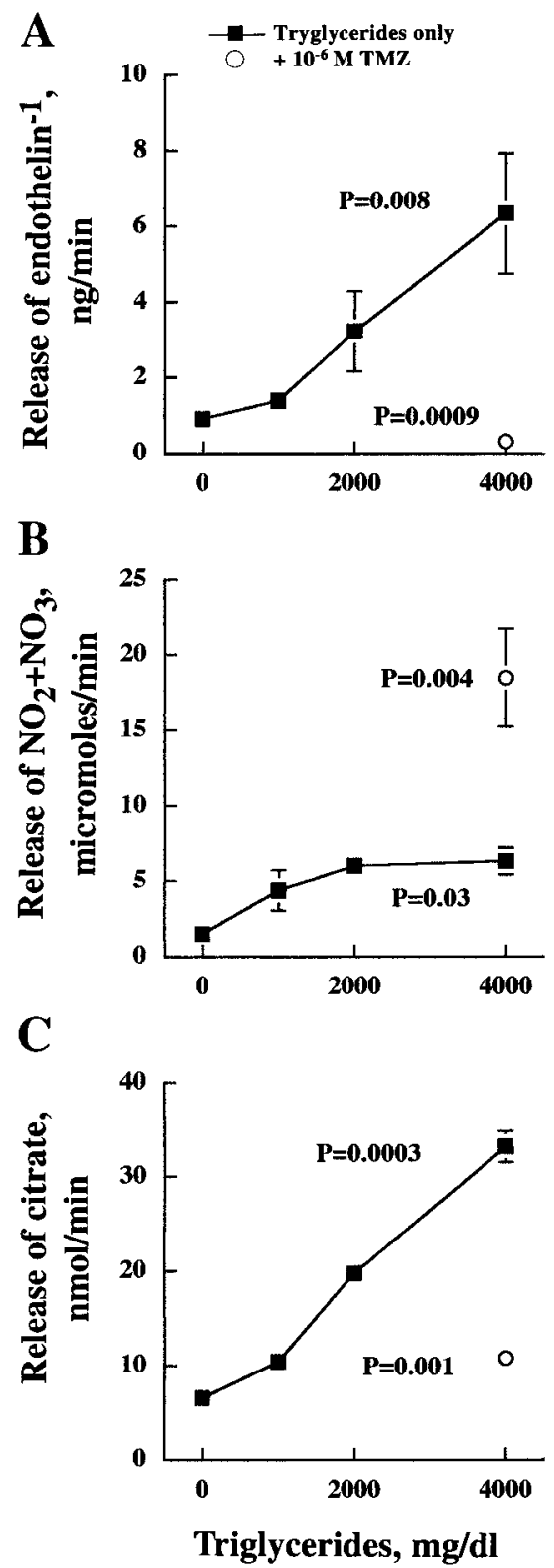

Fig. 3. Releases of endothelin-1 (ET-1) $(A)$, nitrite and nitrate $(B)$, and citrate $(C)$ during reperfusion. Data are means $\pm \mathrm{SE}$ (see Fig. 1).

Figure $4, A$ and $B$, shows the correlation existing between ET-1 release and EDP or the recovery of LVDP.HR measured at the end of the reperfusion. The correlation is statistically significant $(P=0.0002$ and $P=0.01$, respectively). Similarly, a significant correlation is found when substituting EDP or LVDP.HR with either $\operatorname{LVDP}(P=0.002),+\mathrm{dP} / \mathrm{d} t_{\max }(P=0.005)$, or $-\mathrm{dP} / \mathrm{d} t_{\max }(P=0.004)$ but not $\mathrm{CPP}(P=$ not significant).

Figure 5 shows the changes in the $\mathrm{O}_{2}$ uptake-toLVDP.HR ratio in the various groups. Low-flow ischemia significantly decreased that ratio in all groups with respect to baseline $(P<0.007)$. On reperfusion, the $\mathrm{O}_{2}$ uptake-to-LVDP.HR ratio recovered to nearnormal values, with the exception of the $\mathrm{TG}_{4,000}$ group, for which that ratio increased from $0.27 \pm 0.02$ to
$0.55 \pm 0.05 \mu \mathrm{mol} \cdot \mathrm{mmHg}^{-1} \cdot 1,000(P=0.003)$. Venous lactate concentration ([lactate]) at the end of ischemia ranged from 1.6 to $2.3 \mathrm{mmol} / \mathrm{l}$ in all groups without differences among the groups.

\section{DISCUSSION}

In this hyperglycemic, hyperinsulinemic model, elevated [TG] in the medium progressively impairs the postischemic recovery of both systolic and diastolic functions. The impairment is associated with increased ET-1 release. The addition of $10^{-6} \mathrm{M}$ TMZ protects hearts from the deleterious effect of high TG. The protection is associated with blunted ET-1 release and increased $\mathrm{NO}_{\mathrm{x}}$ release.

Critique of the model. By reducing to a reasonable minimum the number of the involved variables, the isolated crystalloid-perfused heart model appears suitable for studying the effects of TG in the ischemicreperfused cardiac muscle. The animals were not pretreated; thus the observations relate to acute metabolic effects. Any interference by neurohormonal factors is excluded because isolated hearts are denervated. Perfusion with blood cell-free media excludes the disturbing effect of neutrophil accumulation and thrombininduced platelet aggregation. Temperature is strictly controlled $\left( \pm 0.5^{\circ} \mathrm{C}\right)$. A constant balloon volume rules out differences in loading conditions. The duration and severity of ischemia are the same in all groups. The changes in vascular resistance are monitored as $\triangle \mathrm{CPP}$ because the flows were the same in all the groups. Although the selected experimental conditions with relatively short ischemia-reperfusion times do not allow for appreciable no reflow, the slight, nonsignificant increase of vascular resistance shown in Fig. 1 indicate that this phenomenon might have occurred on a longer time basis. The changes in diastolic contracture are reflected by $\triangle$ EDP because the balloon volume is fixed at the start of the experiment and kept constant afterward.

Hearts were perfused with media containing glucose and lipids as oxidizable substrates. The experiments reported here were not designed to address the question of their relative contribution to energy production, but the changes in the $\mathrm{O}_{2}$ uptake-to-LVDP. HR ratio reflect different substrate contribution to the rate of ATP synthesis. The fall of that ratio at the end of low-flow ischemia is a consequence of increased substrate-level phosphorylation, as it is evident from the increased venous [lactate]. It is well known that ATP generated from glycolysis represents a substantial portion of total energy production under low-flow ischemia $(5,16)$; this feature was also verified in the same experimental model as that used in this study (45). However, the $\mathrm{O}_{2}$ uptake-to-LVDP·HR ratio returned to near-normal values at the end of reperfusion except for the $\mathrm{TG}_{4,000}$ group. Thus these hearts shifted from carbohydrate to lipid metabolism, a well-known $\mathrm{O}_{2}$ waste effect (32), to a greater extent than those in the other groups. Interestingly, in the $\mathrm{TG}_{4,000}+\mathrm{TMZ}$ group, the ratio was normal, supporting the role of TMZ in shift- 
A

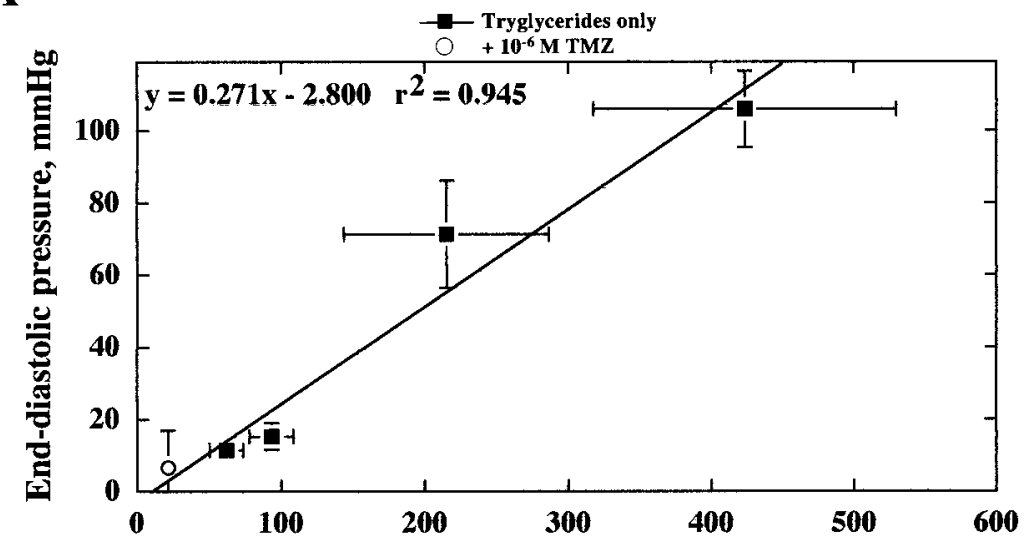

B

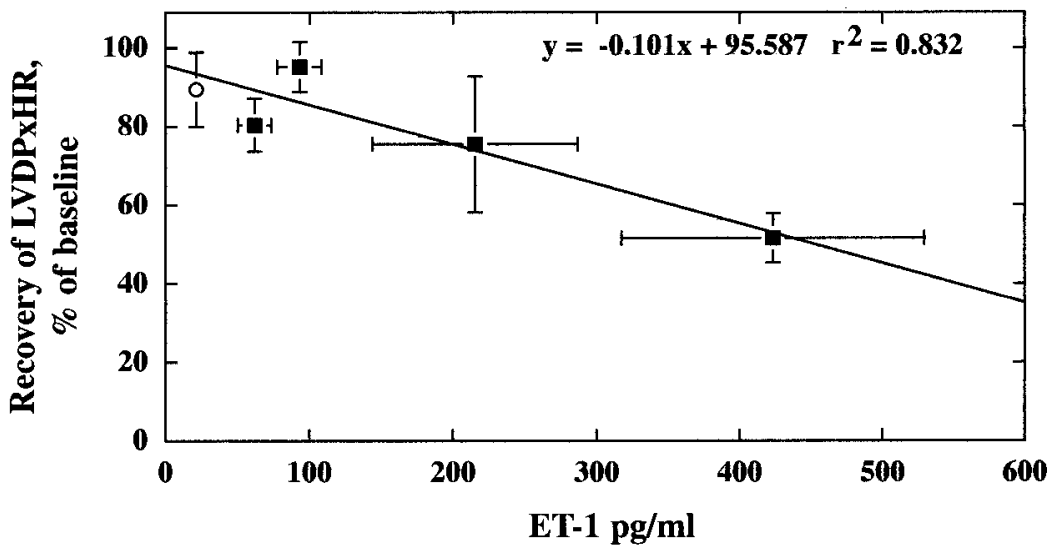

Fig. 4. Correlation between ET-1 release and end-diastolic pressure $(A)$ or the recovery of $\mathrm{LVDP} \cdot \mathrm{HR}(B)$ at the end of reperfusion. $P=0.0002$ and 0.01 , respectively. ing heart metabolism toward the use of glucose rather than lipids (29).

TG-associated injury. The deleterious effect of plasma free fatty acids on myocardial postischemic injury in vivo is well known (34). However, the level of free fatty acids in the perfusion media employed in this study was always $<0.2 \mathrm{mmol} / \mathrm{l}$. Because of the relatively high flow, free fatty acids were undetectable in the venous effluent. However, it is likely that TG were in part hydrolyzed in the vascular compartment, with release of fatty acids into the cytoplasm. Measurement of the citrate release rate provided evidence of this mechanism because this rate reflects the mitochondrial efflux of citrate and is an index of the concentration of substrates feeding acetyl-CoA and oxaloacetate for the citrate synthase reaction (50). The essentially linear relationship between the citrate release rate and [TG] supports the view that TG are partly hydrolyzed into fatty acids, and fatty acids are uptaken into the myocytes. Intracellular fatty acids are known to depress myocardial recovery from ischemia (28), possibly through increased $\beta$-oxidation and decreased glycolysis and/or glucose oxidation. Measurement of citrate release during reperfusion rules out the potentially masking effects of intracellular citrate concentration peaks that might have occurred during ischemia (24).
The blunted citrate release in TMZ-perfused hearts reinforces the hypothesis that the protection afforded by TMZ is exerted through inhibition of $\beta$-oxidation and stimulation of glycolysis and/or glucose oxidation (29). Glycolysis is important in restoring postischemic $\mathrm{Ca}^{2+}$ homeostasis and myocardial function (26), as well as in maintaining membrane integrity (5). This study, however, shows that high TG may impair the postischemic recovery also through increased release of ET-1. Although this hypothesis requires more mechanistic information on how high TG increases ET-1 formation or expression, the present data demonstrates that in this model progressively increased [TG] results in a dose-dependent increase in ET-1 release and that increased ET-1 is highly related to the ischemia-induced performance dysfunction (Fig. 4).

Intralipid is a pool of different types of triglycerides, with fatty acids with variable chain lengths and numbers of cis double bonds. Thus the mechanism of action of TG in the isolated perfused heart requires further work to be elucidated. Previous work (48) pointed out that Intralipid administration during reperfusion is protective, with linoleic acid and phospholipids having complementary actions. However, this situation is different from that in the present study, with Intralipid administered throughout the ischemia-reperfusion 
Fig. 5. Oxygen uptake-to-LVDP·HR ratio during the experimental protocol in the groups. That ratio is expressed relative to baseline value to emphasize intergroup variations. $\# P=0.003$, significant difference with respect to baseline (paired Student's $t$-test). TG, no triglycerides added; $\mathrm{TG}_{1,000}, \mathrm{TG}_{2,000}$, and $\mathrm{TG}_{4,000}$, 1,000, 2,000, and 4,000 mg/dl; $\mathrm{TG}_{4,000}+\mathrm{TMZ}, \mathrm{TG}_{4,000}+$ $10^{-6}$ M TMZ. triglycerides added to medium to concentrations of

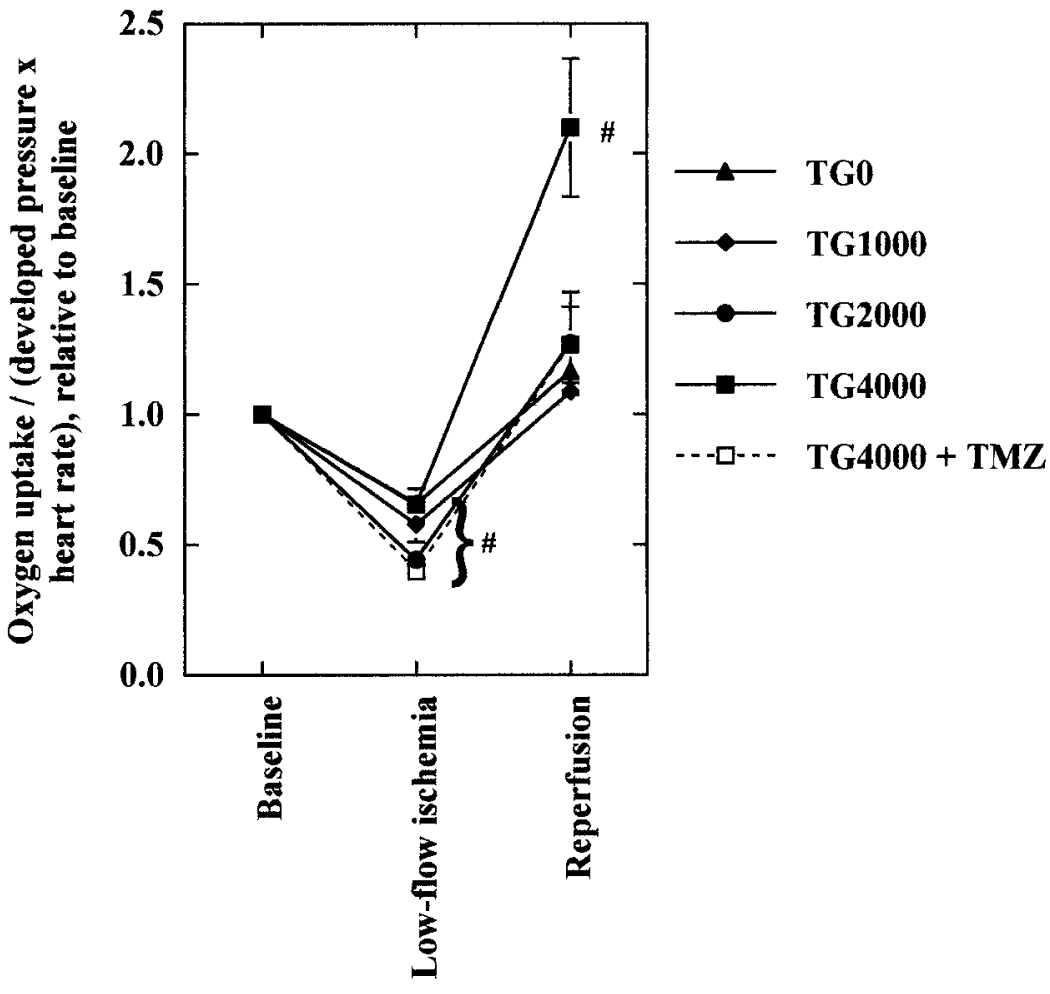

protocol. Regardless of the involved mechanism, it was already demonstrated (42) that under normal conditions, the contribution of phospholipids, cholesterol esters, monoacyl glycerols, and diacyl glycerols to myocardial oxidative metabolism in the presence of TG is $<5 \%$ of the total. Although this work deals with ischemia-reperfusion and not normal conditions, we believe that the effects observed here are to be attributed mainly to TG.

NO. Decreased NO availability plays a significant role in the reperfusion injury even in the absence of blood components, especially at the level of the diastolic function (35). Indeed, supplementation with sodium nitroprusside during hypoxia improves left ventricle relaxation (14) and NO donors inhibit reoxygenation-induced hypercontracture (46). The present data shows that TG increases $\mathrm{NO}_{\mathrm{x}}$ release, probably by a mechanism analogous to that described in small rabbit arteries, by which NO-mediated, shearinduced dilatation opposes the vasoconstriction elicited by increased pressure (38). Indeed, ischemia and reperfusion cause injury to the vascular endothelium, expressed as a reduction in NO release (47). However, it appears from the data shown Fig. 3 that the increase in $\mathrm{NO}_{\mathrm{x}}$ is blunted at $[\mathrm{TG}]=2,000 \mathrm{mg} / \mathrm{dl}$, thereby reducing the possible cardioprotective effect of $\mathrm{NO}$, which is restored by $10^{-6} \mathrm{M}$ TMZ. It was shown (31) that at low doses NO may exert a positive inotropic effect on cardiac function, whereas a relaxation-hastening effect of NO becomes apparent while the dose of NO is increased. Therefore, it remains to be established whether the $\mathrm{NO}_{\mathrm{x}}$ release found in the presence of $\mathrm{TMZ}$ falls within the protective NO dose range. If we assume that the release of $\mathrm{NO}_{\mathrm{x}}$ was constant over time during the $30 \mathrm{~min}$ of reperfusion, then the value of 1,200 $\mu \mathrm{mol} / \mathrm{l}$ divided by $30 \mathrm{~min}$ yields $40 \mu \mathrm{mol} \cdot \mathrm{l}^{-1} \cdot \mathrm{min}^{-1}$ release, which is apparently beneficial to protect hearts after 60-min low-flow ischemia.

$T M Z$. We explored the effect of TMZ at concentrations $\left(10^{-6} \mathrm{M}\right)$ that were previously found efficient with regard to ischemic protection (4). This concentration is within the therapeutic range because it compares with the blood levels obtained in ischemic patients receiving oral treatment (40). In this study, $10^{-6} \mathrm{M}$ TMZ inhibits ET-1 secretion, increases the release of $\mathrm{NO}_{\mathrm{x}}$, and reduces the deleterious effect of high TG.

Several hypotheses, not necessarily exclusive, have been proposed to explain the effect of TMZ. First, by inhibiting the activity of 3-ketoacyl CoA thiolase and the flow through the $\beta$-oxidation, TMZ increases oxidative glucose metabolism (29) (see TG-associated injury). Second, by sparing energy during ischemia, TMZ preserves the ATP pool (1). Third, TMZ reduces the intracellular acidosis caused by ischemia (39). Fourth, studies aimed at assessing the effect of TMZ on $\mathrm{Na}^{+}$$\mathrm{K}^{+}$-ATPase (25) and on mitochondrial $\mathrm{Ca}^{2+}$ uptake (22) showed that this effect occurs only for TMZ levels much higher than those that protect the myocardium. In the present study, it is difficult to assess whether blunted ET-1 release is a consequence of the TMZ protective effect on myocardium or if TMZ inhibits ET-1 release by protecting the endothelium. However, the observation that TMZ greatly increases $\mathrm{NO}_{\mathrm{x}}$ release strongly supports the hypothesis that in this model part of the protection is exerted at the level of TMZ enhances mitochondrial function (12). Other 
the endothelial cells. Indeed, immunocytochemical studies aimed at localizing NO synthase and ET-1 in the coronary vascular bed showed that both occur in the endothelial cells (41). Furthermore, pressure-induced tone is regulated by NO and ET-1 but no interaction between the two factors was evident because they involve different kinds of receptors, i.e., $\alpha_{1^{-}}$and $\alpha_{2}$-adrenoceptors (33).

Study limitation and clinical implications. Although we designed this study to mimic the reduction of coronary blood flow that might occur in atherosclerotic coronary vessels of hyperglycemic, hyperinsulinemic, and hyperlipidemic type II diabetic patients during the postprandial period, extrapolation of our data to the clinical situation is to be made with care. First, responses may be different in normal hearts and hearts from diabetic or hyperlipidemic rats. Second, although uncommon, the situation of [TG] $=4,000 \mathrm{mg} / \mathrm{dl}$ may be found in diabetic hyperlipidemic patients in the postprandial period. This situation is worth studying because the link between hypertriglyceridemia and CHD is best seen in the postprandial period, when patients experience exaggerated lipemia, probably related to the delayed clearance of dietary fats (51). The plasma TG level in the postprandial period is positively correlated (3-4 times) with the fasting TG level (20). Furthermore, normalization of plasma TG is markedly delayed in CHD patients because of the presence of gut-derived plasma lipids.

The use of media with increasing Intralipid contents might in principle alter the vascular tone. However, although resistance increased from $\mathrm{TG}_{0}$ to $\mathrm{TG}_{1,000}$, it remained constant up to $\mathrm{TG}_{4,000}$, suggesting that increased viscosity would not have significantly altered data. Although we cannot rule out the possibility that the presence of TG induces vasodilation, possibly via increased NO production, viscosity may not be a central problem. Indeed, the mean globule size for Intralipid is $340 \mathrm{~nm}$ (G. Arcuri and F. Kabi, unpublished communication), thus in the same order of magnitude of the size of chilomicrons (75-1,000 nm). However, the selected way to report data and evaluate statistics, i.e., by considering [TG] as a continuous variable, takes this issue into account.

In this study, we did not investigate whether the presence of ET-1 receptor antagonists in the perfusion medium is able to reverse the deleterious effects of high TG on postischemic myocardial function. This important issue clearly deserves further work.

In conclusion, high TG progressively impairs the myocardial recovery from low-flow ischemia. The impairment is significantly related to the release of ET-1, which appears to mediate the mechanism leading to injury. TG also increases the release of NO but not sufficiently to protect the heart from reperfusion injury. By further increasing NO release, $1 \mu \mathrm{mol} / \mathrm{TMZ}$ prevents ET-1 release and reverses the harmful myocardial effect of TG. By providing experimental evidence of a link among elevated TG, ET-1, and myocardial ischemia-reperfusion injury, this study supports the epidemiological evidence that suggests that the situation characterized by elevated plasma TG is associated with increased cardiovascular risk independent of factors such as hyperglycemia and elevated plasma cholesterol.

This study was supported in part by the Ministero dell' Università e della Ricerca Scientifica e Tecnologica Grant "Molecular mechanisms of the protection of the ischemic heart," in part by Italian Ministry of Health Grant RF99.52 "Invalidant Complications of Diabetes," and in part by a grant from the Istituto di Ricovero e Cura a Carattere Scientifico, Hospital San Raffaele.

\section{REFERENCES}

1. Allibardi S, Chierchia S, Margonato V, Merati G, Neri G, Dell'Antonio G, and Samaja M. Effects of trimetazidine on metabolic and functional recovery of post-ischemic rat hearts. Cardiovasc Drugs Ther 12: 543-549, 1998.

2. Anfossi G, Cavalot F, Massucco P, Mattiello L, Mularoni E, Hahn A, and Trovati M. Insulin influences immunoreactive endothelin release by human vascular smooth muscle. Metabolism 42: 1081-1083, 1993.

3. Austin MA, McKnight B, Edwards KL, Bradley CM, McNeely MJ, Psaty BM, Brunzell JD, and Motulsky AG. Cardiovascular disease mortality in familial forms of hypetriglyceridemia: a 20-year prospective study. Circulation 101: 2777-2782, 2000.

4. Boucher FR, Hearse DJ, and Opie LH. Effects of trimetazidine on ischemic contracture in isolated perfused rat hearts. J Cardiovasc Pharmacol 24: 45-49, 1994.

5. Bricknell OL and Opie LH. Effects of substrates on tissue metabolic changes in the isolated rat heart during underperfusion and on release of lactate dehydrogenase and arrhythmias during reperfusion. Circ Res 43: 102-114, 1978.

6. Brunner F. Interaction between nitric oxide and endothelin-1 in ischemia/reperfusion injury of rat heart. J Mol Cell Cardiol 29: 2363-2374, 1997.

7. Brunner F, du Toit EF, and Opie LH. Endothelin release during ischemia and reperfusion of isolated rat hearts. $J \mathrm{Mol}$ Cell Cardiol 24: 1291-1305, 1992.

8. Brunner F, Leonhard B, Kukovetz WR, and Mayer B. Role of endothelin, nitric oxide and L-arginine release in ischemia/ reperfusion injury of rat heart. Cardiovasc Res 1997: 60-66, 1997.

9. Brunner F and Opie LH. Role of endothelin A receptors in ischemic contracture and reperfusion injury. Circulation 97: 391-398, 1998

10. Caligiuri G, Levy B, Pernow J, Thoren P, and Hansson GK. Myocardial infarction mediated by endothelin receptor signaling in hypercholesterolemic mice. Proc Natl Acad Sci USA 96: 6920-6924, 1999.

11. Cunningham MJ, Apstein CS, Weinberg EO, Vogel WM, and Lorell BH. Influence of glucose and insulin on the exaggerated diastolic and systolic dysfunction of hypertrophied rat hearts during hypoxia. Circ Res 66: 406-415, 1990.

12. Demaison L, Fantini E, Sentex E, Grynberg A, and Athias P. Trimetazidine: in vitro influence on heart mitochondrial function. Am J Cardiol 76: 31B-37B, 1995.

13. Detry JMR and Leclerq PJ. Trimetazidine European multicenter study versus propranolol in stable angina pectoris: contribution of Holter electrocardiographic ambulatory monitoring. Am J Cardiol 76: 8B-11B, 1995.

14. Draper NJ and Shah AM. Beneficial effects of a nitric oxide donor on recovery of contractile function following brief hypoxia in isolated rat hearts. J Mol Cell Cardiol 29: 1195-1205, 1997.

15. Drexler H. Nitric oxide and coronary endothelial dysfunction in humans. Cardiovasc Res 43: 572-579, 1999.

16. Eberli FR, Weinberg EO, Grice WN, Horowitz GL, and Apstein CS. Protective effect of increased glycolytic substrate against systolic and diastolic dysfunction and increased coronary resistance from prolonged global underperfusion and reperfusion in isolated rabbit hearts perfused with erythrocyte suspensions. Circ Res 68: 466-481, 1991. 
17. Ferri C, Pittoni V, Piccoli A, Laurenti O, Cassone MR, Bellini C, Properzi G, Valesini G, De Mattia G, and Santucci A. Insulin stimulates endothelin-1 secretion from human endothelial cells and modulates its circulating levels in vivo. J Clin Endocrinol Metab 80: 829-835, 1995.

18. Fontbonne A, Eschwege E, Cambien F, Richard JL, Ducimetiere P, Thibult N, Warnet JM, Claude JR, and Rosselin GE. Hypertriglyceridemia as a risk factor of coronary heart disease mortality in subjects with impaired glucose tolerance or diabetes. Diabetologia 32: 300-304, 1989.

19. Gonon AT, Wang QD, Shimizu M, and Pernow J. The novel non-peptide selective endothelin A receptor antagonist LU 135,252 protects against myocardial ischemic and reperfusion injury in the pig. Acta Physiol Scand 163: 131-137, 1998.

20. Groot PHE, Van Stiphout WAHJ, and Krauss XH. Postprandial lipoprotein metabolism in normolipemic men with and without coronary disease. Arterioscler Thromb 11: 653-662, 1991.

21. Grover GJ, Dzwonczyk S, and Parham CS. The endothelin-1 receptor antagonist BQ-123 reduces infarct size in a canine model of coronary occlusion and reperfusion. Cardiovasc Res 27: 1613-1618, 1993.

22. Guarnieri C, Finelli C, Zini M, and Muscari C. Effects of trimetazidine on the calcium transport and oxidative phosphorylation of isolated rat heart mitochondria. Basic Res Cardiol 92: 90-95, 1997.

23. Hasdai D, Kornowski R, and Battler A. Endothelin and myocardial ischemia. Cardiovasc Drugs Ther 8: 589-599, 1994.

24. Hassel B, Ilebbek A, and Tonnessen T. Cardiac accumulation of citrate during brief myocardial ischemia and reperfusion in the pig in vivo. Acta Physiol Scand 164: 53-59, 1998.

25. Hisatome I, Ishiko R, Tanaka Y, Kosaka H, Hasegawa J, Yoshida A, Kotake H, Mashiba H, and Arita M. Trimetazidine inhibits $\mathrm{Na}^{+}, \mathrm{K}^{+}$-ATPase activity, and overdrives hyperpolarization in guinea-pig ventricular muscles. Eur J Pharmacol 195: 381-388, 1991.

26. Jeremy RW, Koretsune Y, Marban E, and Becker LC. Relation between glycolysis and calcium homeostasis in postischemic myocardium. Circ Res 70: 1180-1190, 1992.

27. Kameda K, Matsuzawa Y, Kubo M, Ishikawa K, Maejima I, Yamamura T, Yamamoto A, and Tarui S. Increased frequency of lipoprotein disorders similar to type III hyperlipoproteinemia in survivors of myocardial infarction in Japan. Atherosclerosis 51: 241-249, 1984.

28. Kantor PF, Dyck JRB, and Lopaschuk GD. Fatty acid oxidation in the reperfused ischemic heart. Am J Med Sci 318: 3-14, 1999

29. Kantor PF, Lucien A, Kozak R, and Lopaschuk GD. The antianginal drug trimetazidine shifts cardiac energy metabolism from fatty acid oxidation to glucose oxidation by inhibiting mitochondrial long-chain 3-ketoacyl coenzyme A thiolase. Circ Res 86: $580-588,2000$.

30. Kyriakides ZS, Markianos M, Iliodromitis EK, and Kremastinos DT. Vein plasma endothelin-1 and cyclic GMP increase during coronary angioplasty is related to myocardial ischemia. Eur Heart J 16: 894-898, 1995.

31. Mohan P, Brutsaert DL, Paulus WJ, and Sys SU. Myocardial contractile response to nitric oxide and cGMP. Circulation 93: 1223-1229, 1996

32. Neely JR and Morgan HE. Relationship between carbohydrate and lipid metabolism and the energy balance of heart muscle. Annu Rev Physiol 36: 413-459, 1974.

33. Nguyen TD, Vequaud $\mathbf{P}$, and Thorin E. Effects of endothelin receptor antagonists and nitric oxide on myogenic tone and alpha adrenergic-dependent contractions of rabbit resistance arteries. Cardiovasc Res 43: 755-761, 1999.
34. Oliver MF and Opie LH. Effects of glucose and fatty acids on myocardial ischemia and arrhrythmias. Lancet 343: 155-158, 1994.

35. Paulus WJ and Shah AM. NO and diastolic function. Cardiovasc Res 43: 595-606, 1999.

36. Piatti PM, Monti LD, Conti M, Baruffaldi L, Galli L, Phan CV, Guazzini B, Pontiroli AE, and Pozza G. Hypertriglyceridemia and hyperinsulinemia are potent inducers of endothelin-1 release in humans. Diabetes 45: 316-321, 1996.

37. Piatti PM, Monti LD, Galli L, Fragasso G, Valsecchi G, Conti M, Gernone F, and Pontiroli AE. Relationship between endothelin-1 concentration and metabolic alterations typical of the insulin resistance syndrome. Metabolism 49: 748-752, 2000.

38. Pohl U, Herlan K, Huang A, and Bassenge E. Nitric oxide mediated shear-induced dilation opposes myogenic vasoconstriction in small rabit arteries. Am J Physiol Heart Circ Physiol 261: H2016-H2023, 1991.

39. Reymond F, Steyaert G, Carrupt PA, Morin D, Tillement JP, Girault HH, and Testa B. The pH-partition profile of the anti-ischemic drug trimetazidine may explain its reduction of intracellular acidosis. Pharm Res 16: 616-624, 1999

40. Royer RJ, Royer Morrot MJ, Bannwarth B, Giffard S, and Harpey C. Evaluation des concentrations à l'état d'équilibre et de la fixation globulaire de la trimétazidine. Vastarel $20 \mathrm{mg}$ et l'ischémie myocardique. Gaz Med France 91: 69-70, 1984.

41. Rubino A, Loesch A, and Burnstock G. Nitric oxide and endothelin-1 in coronary and pulmonary circulation. Int Rev Cytol 189: 59-93, 1999.

42. Saddik M and Lopaschuk GD. Myocardial triglyceride turnover and contribution to energy substrate utilization in isolated working rat hearts. J Biol Chem 266: 8162-8170, 1991.

43. Sakai S, Miyauchi T, and Yamaguchi I. Long-term endothelin receptor antagonist administration improves alterations in expression of various cardiac genes in failing myocardium of rats with heart failure. Circulation 101: 2849-2853, 2000.

44. Samaja M, Allibardi S, de Jonge R, and Chierchia S. Highenergy phosphates metabolism and recovery in reperfused ischemic hearts. Eur J Clin Invest 28: 983-988, 1998.

45. Samaja M, Casalini S, Allibardi S, Corno A, and Chierchia S. Regulation of bioenergetics in $\mathrm{O}_{2}$-limited isolated rat hearts. J Appl Physiol 77: 2530-2536, 1994

46. Schluter KD, Weber M, Schraven E, and Piper HM. NO donor SIN-1 protects against reoxygenation-induced cardiomyocyte injury by a dual action. Am J Physiol Heart Circ Physiol 267: H1461-H1466, 1994

47. Tsao PS and Lefer AM. Time course and mechanism of endothelial dysfunction in isolated ischemic- and hypoxic-perfused rat hearts. Am J Physiol Heart Circ Physiol 259: H1660-H1666, 1990.

48. Van der Velde M, De Wolff M, and Wouters PF. Effects of lipids on the functional and metabolic recovery from global myocardial stunning in isolated rabbit hearts. Cardiovasc Res 48: 129-137, 2000.

49. Verdon CP, Burton BA, and Prior RL. Sample pretreatment with nitrate reductase and glucose-6-phosphate dehydrogenase quantitatively reduces nitrate while avoiding interference by $\mathrm{NADP}^{+}$when the Griess reaction is used to assay for nitrate. Anal Biochem 224: 502-508, 1995.

50. Vincent G, Comte B, Poirier M, and Des Rosiers C. Itrate release by perfused rat hearts: a window on mitochondrial cataplerosis. Am J Physiol Endocrinol Metab 278: E846-E856, 2000.

51. Zilversmit DB. Atherosclerosis: a postprandial phenomenon. Circulation 60: 473-485, 1979. 